\title{
Teaching severely autistic children to recognise emotions: Finding a methodology
}

\author{
Salima Y Awad Elzouki \\ Leeds Metropolitan University \\ Headingley Campus \\ Leeds LS6 3QS, UK \\ +441132832600 \\ s.elzouki@leedsmet.ac.uk
}

\author{
Marc Fabri \\ Leeds Metropolitan University \\ Headingley Campus \\ Leeds LS6 3QS, UK \\ +441132832600 \\ m.fabri@leedsmet.ac.uk
}

\author{
David J Moore \\ Leeds Metropolitan University \\ Headingley Campus \\ Leeds LS6 3QS, UK \\ +441132832600 \\ d.moore@leedsmet.ac.uk
}

\begin{abstract}
This paper presents part of our wider research project concerning the design, development and evaluation of computer systems for children with autism. Research currently being carried out concerns how children with autism recognise human facial expressions of emotion and how the use of computerbased animated characters might help them in this recognition. The context for the research is a primary school unit of children with severe autism and moderate to severe learning difficulties. We present results of a preliminary study designed to establish a baseline for the abilities of each child, and describe the methodology considerations that arose during and after the study. The merit of participant observers is discussed, and links to action research are pointed out.
\end{abstract}

\section{Categories and Subject Descriptors}

H.1.2 [User/Machine Systems]: Human factors, Human Information Processing

\section{General Terms}

Measurement, Experimentation, Human Factors

\section{Keywords}

Autism, Emotions, Avatars, Social Networking

\section{INTRODUCTION}

The literature has different views about what precisely "Autism" is. Leo Kanner in 1943 invented the label "early infantile autism" to describe children who "had never been participants in that social world" [8]. Hans Asperger in 1944 used the term "autistic" or "autism" to describe the more able children who "found it difficult to fit in socially" [8]. This less severe form of autism is since referred to as Asperger Syndrome (AS). The National Autistic Society recognises several subgroups of autism. Having an autistic spectrum disorder (ASD) is a "complex lifelong developmental disability" [21].

The deficit of social proficiencies is still considered as one of autism's specific concerns and one of the common views of the nature of autism. For example Aarons \& Gittens [1] think that the "social disability is the essence of autism". Many students with Autism or ASD have learning difficulties or learning disabilities [16][21]. This might explain the suggestion of Baron-Cohen \& Bolton [6] that to the general public, autism is

(C) Salima Elzouki, Marc Fabri, David Moore, 2007 Published by the British Computer Society

Volume 2 Proceedings of the 21st BCS HCI Group Conference HCI 2007 I ancaster I Jniversitv 3-7 Sentemher 2007 often perceived as a "mental handicap". Wing [26] proposed that the social difficulties that characterise children with autism ban best be described as a "Triad of Impairments". These impairments are as follows:

1. Firstly there is a communication impairment: people with autism tend to have difficulty understanding and also using verbal and non verbal communication

2. Secondly a social impairment: autistic people find it difficult to join and sympathize with other people.

3. Thirdly there is an impairment of social imagination. People with autism have rigidity in language, thinking and manners.

Howlin et al. [14] suggest that this triad of impairments is underpinned by a "Theory of Mind deficit" (ToM) which is the ability to mind-read and surmise the thoughts, beliefs, desires and intentions of others. Peterson et al [20] argue that the understanding of desires precedes the understanding of beliefs. Therefore, understanding that other people have desires and emotions is also an important part of ToM.

The incidence of autism and its related behaviours is increasing. In 2004 the Autism Society of America estimated autism to occur in 2 - 6 per 1,000 births, with boys being affected four times that of girls [2]. However, more recently the reported incidence rose to 1 per 150 in the US [3] and to 1 per 100 in UK [21]. Autism is not limited to the Western world. However, many developing countries do not recognise autism. Libya, for example, has only recently recognised autism as a separate diagnosis but figures for incidence are not yet available.

\section{EDUCATION AND TECHNOLOGY FOR PEOPLE WITH AUTISM}

The reason behind the rise of autism incidences is unknown but it is clear that there is an urgent need for help and intervention. Education is seen as the key solution to overcoming autism impairments and it is also seen as the most important part of any attempt to help people with autism attaining a good base to live a better and more cheerful life [1][18][20]. Recently, there has been an interest in research using computer approaches with people with autism [19]. This is partly based on the fact that people with autism are naturally attracted to and interested in computer approaches [19][22][25]. This might be due to the beneficial characteristics that computer environments might offer to people with autism. Computers can, for example, provide individualised tutoring where the instructions could be repeated to the user or the student without tedium and without potentially counter-productive human intervention [19][24][20]. Much of recent research concerns social skills education for autistic people as well as addressing ToM problems. However, it has been argued that there is an urgent need for more programs that directly address autism specific 
impairments. [20][19][4]. Also there is little work looking at the more severe end of the spectrum [17] which is where the work reported in this paper comes in. Bosseler and Massaro [7], for example, confirmed that children with autism can successfully use computer-based animated characters to increase their vocabulary.

Whether children with severe autism can use such characters to improve their knowledge of emotions is the key question behind this research. We are investigating whether and how children with severe autism can recognise, or learn to recognise, emotions from human facial expressions. These emotions are presented by real people (photographs) as well as computer-generated characters and the work builds on work by Fabri's [11] investigation of using emotionally expressive avatars for social networking. The ultimate aim of the current work is to engage children with autism in social networking systems to help them overcome some of their social impairments in a safe environment. In this paper we present preliminary results of a study designed to establish a baseline for emotion recognition.

\section{CHILDREN CASE STUDIES}

The research is being conducted in a special unit at a local school (Leeds, UK) for children with severe autism and moderate to severe learning difficulties. Before outlining our actual work and experimental study, we believe it is crucial to present the diversity of the children in the school, and illustrate how wide the spectrum of autism is. Realising and responding to this had a major impact on our research methodology.

The total number of children in the unit is 11 , divided into two classes: In Key Stage 1 (KS1) there are 6 children ( 5 boys $\& 1$ girl) aged 6 to 8 years. In Key Stage 2 (KS2) there are 5 children ( 4 boys $\& 1$ girl) aged 9 to 11 years. In the unit, these children follow a tightly organised daily routine in an attempt to maintain a predictable environment and minimise sudden changes in their behaviour. That does not mean, however, that unexpected changes do not happen, and in reality some children find it hard to cope even with this predictable and familiar environment depending on their mood at certain times and on certain days.

Due to the ethical considerations when working with children in general, and impaired children in particular, all parents were asked for consent after being fully informed of the aims and procedure of the study (see section 5 below). Parents for 8 children agreed for their children to participate (5 from KS1, 3 from KS2). In the next section we present characteristics of these 8 children. The names are not their real names.

\section{Kareem, 7 years}

Kareem has a severe language impairment as a result of which he finds it hard to communicate with others. He usually points to objects he wants, uses symbols available in the classroom, or says words in his own language. Kareem likes using a computer and is focussed and interested in the computer whenever he has the opportunity to play with it. However, he does not like sharing the computer with others.

\section{Moftah, 7 years}

In addition to autism Moftah's behaviour is sometimes aggressive and challenging. Moftah has a good articulation and pronunciation when compared to Kareem. While he cannot formulate full sentences, he can say what he wants very clearly in singular words. He sometimes becomes incomprehensible though and appears to talk to objects close to him, followed by giggling. Moftah is interested in computers and does not like to share the computer with other children.

\subsection{Jamal, 8 years}

Jamal is on a language level similar to Moftah. He can say clearly what he wants in one or two words. Jamal is sometimes aggressive and scratches other children or teaching staff in the face. Somewhat untypical for severely autistic children, Jamal maintains good eye-contact with who he talks to. He exposes the "Echolalia" feature of autism where he repeats what other people say to him. Jamal likes to draw, in particular animals. He has a talent to copy what is placed in front of him in a matter of minutes and to near perfection. Children with such unusual abilities are often referred to as "savants". Jamal has no interest in computers and does not know how to use one.

\subsection{Nahla, 8 years}

Nahla is the only girl in the KS1 class. Her diagnosis changed recently from autism to "attachment disorder". Compared to the other KS1 children, Nahla is the most able child with regards to communication. She acts "neuro typical" (NT) in the school environment where she likes to join in the class activities. Occasionally, Nahla is very aggressive and is then difficult to calm down if she does not get her way. This may culminate in her slapping other children or teaching staff. Like Jamal, Nahla has no interest in computers.

\subsection{Nasser, 6 years}

Nasser is the youngest child in the KS1 class. He joined the unit only recently. In class Nasser would usually be in his favourite corner of the room. He rarely moves from there unless he needs something. While in "his" corner, Nasser makes clicking noises with his mouth, a unique behaviour in the class. Nasser is generally well behaved and non-aggressive. When there is something he does not like his response is usually to cry. He can say what he wants in singular words, like Jamal and Moftah. Nasser has no interest in computers but likes watching videos and DVDs.

\subsection{Tarek, 9 years}

Tarek's visible behaviour is different from the other children. He shows some very typical features of autism e.g. keeping his ears blocked most of the time, turning his face away from people near him or flapping hands or objects around him [cf. 26]. He spends most of his time in class standing on his own, in a certain spot in the room, moving away only when he needs something. Tarek likes to hum and sing parts of movie songs to others, or sometimes with others. He is interested in computers and his typical behaviour when using one is to stand in front of the screen, close one of his ears with one hand, and play with the mouse or keyboard with the other hand. He likes to listen to songs on the computer and he can move the mouse, minimise, maximise and close down computer windows.

\subsection{Yzan, 10 years}

Yzan is a quiet boy whose voice is rarely heard in class. He has problems communicating and is in the early stages of learning to speak. He is aloof most of the time in class, and likes being on his own, looking thoroughly at walls and glass windows. Yzan likes to play computer games, jumping from one scene to another without finishing any game task. When he loses interest he will immediately turn off the computer. He may repeat this pattern several times during one day. Tarek likes the sounds coming from the computer and he often puts up the volume to highest setting.

\subsection{Nabeel, 9 years}

Nabeel has autism with moderate learning difficulties. He has good speaking abilities compared to the other children. Nabeel can construct full sentences and say what he wants very clearly. 
However, he sometimes utters words and sounds that cannot be understood, and appears to be talking to some invisible person or object next to him - in a similar way to Moftah. Sometimes he stays aloof from the others and spends the time sitting in front of the window, or he lies down on the floor. Nabeel is interested in computers and spends time sitting down and playing games. He uses the mouse and follows links in order to win a game or complete a task

\subsection{Reflection}

As evidenced above, behaviours and abilities under the umbrella of the Autistic Spectrum Disorder are wide and varied. Looking at each child individually was crucial to inform our methodology and study design, and it also helped us to set the preliminary results of our work into context. In the next section we describe what methodology we used and how we arrived there.

\section{METHODOLOGY}

Based on the above we realised that these children were special and individual in many ways. The debate about which methodology to use for an in depth investigation into how these children could be helped to overcome some of their impairments represented a major part of the initial research. Due to the small number of children, quantitative data was not expected to be statistically relevant. In any case, the individual differences between the children, and the inherently social and personal nature of autism called for detailed qualitative research methods. In the next sections we describe our "journey" to identify the right methodology which we hope is of interest to other practitioners.

\subsection{Participation during observation}

In research, observation is a fundamental method of gathering data, aiming to gather first hand information in a naturally occurring situation. We initially intended to use non-participant observation where the observer is a neutral outsider, commonly used to avoid the observer influencing the events taking place. For a number of weeks the children were observed within the daily basic sessions at school to get to know how they behaved in their daily routine. Some of the case study characteristics mentioned above were the output of these observations. However, it became obvious that to engage the children in any experimental activity, one had to become part of their daily routine. Further, it was difficult to stay neutral due to the small group size and it was during this time that the primary author started to sympathise with the children. Towards the more severe end of the autistic spectrum it seems to be impossible to observe without getting to know the child over a longer period of time if any type of response from, or interaction with, the children is to be achieved.

In HCI, “co operative user observation” is considered a most suitable method to evaluate prototype interfaces with children [9]. We argue, therefore, that to apply this method with this user group the observer requires detailed knowledge of each child's needs. Indeed, familiarity between the child and the observer is important to avoid distress or upset during any computer intervention. A combination of both participant (neutral observer) and non-participant (involved observer) observations was adopted, and a detailed case study profile was created for each child. The observer effectively became a teaching assistant in order to create a sufficient level of familiarity and trust.

\subsection{Relationship to Action Research}

It could be argued that there is a loop of cycles within above approach which is related to the Action Research method [12]. In action research, one goes through several cycles namely a) observe events occurring in real life, b) reflect on these and identify that there is a problem, c) plan how the problem could be solved or the situation improved on, and finally d) act and start observing again. We argue that on an individual child's basis, we can follow a similar cycle and apply interventions in order to assess the child's abilities and observe any development or learning taking place as a result. The study described below is the first intervention and it aimed to establish a baseline for what the participating children were able to do, and where the next cycle could lead them.

\section{RECOGNITION STUDY}

The literature concerning children with autism and emotional understanding suggests that these children have difficulty in creating and producing emotional expressions, they are also poor in reading and understanding other's facial expressions [14][15]. This might explain their weaknesses in understanding other people's mental states i.e. the Theory of Mind (ToM) impairment [5]. To overcome this impairment, [14] considered recognising human facial expressions from photographs as the first level of acquiring emotional understanding. The range of impairments, abilities and preferences of the children participating in this research meant that there could not be one single piece of software that would suit all children. To establish a baseline for what each child is capable of, we followed the approach taken by [14] who presented children with pictures of people showing facial expressions of emotions corresponding with happy, sad, angry and frightened (see Fig 1 below).
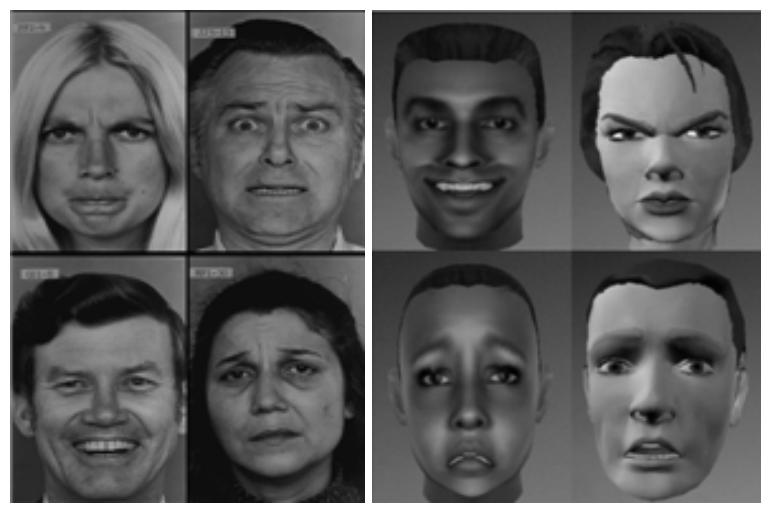

Figure 1. Material used in Stages 1 and 2

\subsection{Procedure}

The place, time and the date of the study had been agreed with the teacher before starting any stages of the study. Participating children were put in a familiar and predictable environment in order to make the experiment part of their daily routine as much as possible. A laptop was used and all sound was recorded using a digital recorder.

At the time of the study, the children were asked individually by the staff if they like to work on the computer. The ones who were interested came to the workstation area and sat down. A red "wait" symbol that is usually used by the staff to encourage turn-taking during computer usage was used in the study.

Each child was shown the photos in a $2 \times 2$ matrix on a computer screen ([14] used laminated paper) and asked the same question about each emotion, e.g. "can you point to the happy face?". After being shown the first set of photographs (identical to the 
black \& white photographs Howlin [14] used), the children were in stage 2 presented with screen shots of computer generated faces showing expression for the same set of emotions, as created and validated by [11]. In a third stage, the children were shown the same set of computer-generated faces from stage 2 after rotating them and with different genders representing the emotions, to avoid order and gender prototyping problems.

By studying pre-validated emotion representations with such a user group, we are arguably testing the standard in extremis, and hence potentially enabling the standard to be strengthened. Lessons from the use of the technology in extraordinary human computer interaction might then lead to helpful development of the technology for "general” use [cf. 13].

\subsection{Results}

Results were inconclusive. Only one child (Moftah) recognised all expressions. While Kareem recognised all of the photographs, he struggled with the computer-generated faces. Interestingly, Nahla's results were reversed, indicating a possible link with her attachment disorder. Nabeel was successful only during stage 2 . Several children did not cooperate at all, or only during some stages.

\section{CONCLUSIONS AND FURTHER WORK}

The results obtained in the recognition study show that each child is individual in their ability to recognise emotions. The number of instances of non-cooperation during the experiment indicates the difficulties that working with such children can involve, even when the children know the observing researcher well. Further, the case studies revealed that because of their severe autism, the children have significantly different abilities of social interaction and communication. Based on both the quantitative and qualitative data we will now create a programme for each child, aimed at their current level of ability and taking advantage of their individual interests. Jamal's interest in animal drawings, for example, could provide a way to get him interested in the facial expressions when they are somehow related to animals. Nahla, who had difficulty recognising the human photographs, could be presented with computer-generated faces with a higher degree of realism than the ones used so far. Eventually we hope to evidence progress for each child, at their level, and potentially be able to identify patterns in their behaviour that recur across several children.

\section{REFERENCES}

[1] Aarons, M., Gittens, T. (1998). Autism: A social skills approach for children and adolescents. Oxford: Winslow

[2] Autism Society of America (2004). Statistics for 2004. http://www.autism-society.org

[3] Autism Society of America (2007). Statistics for 2007. http://www.autism-society.org

[4] Beardon, L., Parsons, S., \& Neale, H. (2001). An interdisciplinary approach to investigating the use of virtual reality environments for people with Asperger syndrome. Education \& Child Psych. 18(2), 53-62.
[5] Baron-Cohen, S. (1996). Psychology in action; Autism

[6] Baron-Cohen S. \& Bolton B. (1993), Autism: the facts, Oxford

[7] Bosseler, A., Massaro, D.W. (2003). Development and Evaluation of a Computer-Animated Tutor for Vocabulary and Language Learning, Journal of Autism and Development Disorders, 33(6), 653-672.

[8] Cumine V, Leach J and Stevenson G. (2000), Autism in the early years: a Practical Guide.

[9] Dix, A. , Finlay, J., Abowd, G., Beale, R. (1998). HumanComputer Interaction, 3rd edition

[10] Ekman and Friesen (1975). Pictures of Facial Affect. CDROM, University of California

[11] Fabri (2006). Emotionally Expressive Avatars for Collab. Virtual Environments. PhD Thesis. Leeds Met University

[12] Herr, Kathryn and Anderson (2005). The Action Research Dissertation. London. Sage

[13] Hobbs, D.J., Moore, D.J. (1998) Human computer interaction. FTK Publishing, London

[14] Howlin, P., Baron-Cohen, S., Hadwin, J. (1999) Teaching Children with Autism to Mind-Read, A Practical Guide for Teachers and Parents, John Wiley and Sons

[15] Irish Autism Society (1995). A Story of Autism. Booklet

[16] Jordan, P. Jones, G. Morgan, H (2001), The Foundation for People with Learning Disabilities.

[17] Moore (2007). Computer Systems for People with Autism; Internal Report, Leeds Met University

[18] Moore D, McGrath P, Thorpe J (2000) Computer Aided Learning for People with Autism Innovations in Education and Training International, 37(3), 218-228

[19] Moore D, Cheng Y, McGrath P, Powell N (2004). CVE Technology for People with Autism; Internal Report, Leeds Met University.

[20] Moore D, Taylor J (2000) Interactive multimedia systems for people with autism. J. Educ. Media, 25, 169-177

[21] The National Autistic Society, http://www.nas.org.uk

[22] Parsons, S., Mitchell, P. (2002). The potential of virtual reality in social skills training for people with autistic spectrum disorders, J of Intell. Disab. Res., 46, 430-443

[23] Peterson, C.C., Wellman H.M. \& Liu D. (2005). Steps in Theory- of-Mind Development for Children with Deafness or Autism. Child Development, 76(2) 502-517.

[24] Silver, M., \& Oakes, P. (2001). Evaluation of a new computer intervention to teach people with autism or Asperger Syndrome to recognise and predict emotions in others. Autism, 5(3), 299-316.

[25] Tucker L (1997). Primary Education, Communication, Winter, pp13-15

[26] Wing, L. (1996) The Autism Spectrum: A Guide for Parents and Professionals, London, Constable 